\title{
Consumo e Digestibilidades Aparentes Totais e Parciais de Nutrientes em Novilhos Alimentados com Dietas Contendo Vários Níveis de Concentrado ${ }^{1}$
}

\author{
Luís Carlos Vinhas Ítavo ${ }^{2}$, Sebastião de Campos Valadares Filho ${ }^{3}$, Fabiano Ferreira da Silva ${ }^{4}$, \\ Rilene Ferreira Diniz Valadares ${ }^{3}$, Maria Ignez Leão ${ }^{3}$, Paulo Roberto Cecon ${ }^{3}$ Camila Celeste Brandão \\ Ferreira Ítavo ${ }^{5}$, Eduardo Henrique Bevitori Kling de Moraes ${ }^{6}$, Pedro Veiga Rodrigues Paulino ${ }^{6}$
}

RESUMO - Objetivou-se estudar o consumo e as digestibilidades totais e parciais de nutrientes em bovinos. Foram utilizados cinco bovinos da raça Nelore, não-castrados, com $165 \mathrm{~kg}$, fistulados no rúmen, abomaso e íleo. O delineamento foi em blocos casualizados, com quatro tratamentos e cinco períodos de coleta. Os tratamentos consistiram de quatro níveis de concentrado na dieta (20, 40, 60 e $80 \%$ ). O volumoso utilizado foi feno de capim-Tifton 85 (Cynodon dactylon (L.) Pers.). Somente os consumos de FDN e FDA apresentaram redução linear com o aumento do nível de concentrado da dieta. Os consumos de MS e NDT foram em média de 3,45 e 2,24 $\mathrm{kg} /$ dia, respectivamente. Os coeficientes de digestibilidade aparente da MS, MO e CHOT aumentaram linearmente, em função do nível de concentrado na dieta. Enquanto as digestibilidades aparentes da PB e EE apresentaram média de 59,50 e 70,81\%, respectivamente. Houve redução linear nos coeficientes de digestibilidade da FDN e FDA. O nível de concentrado não afetou a digestão ruminal da PB e EE, cujas médias foram 4,80 e 1,41\%, respectivamente. A digestibilidade ruminal da FDN apresentou redução linear com o aumento do nível de concentrado na dieta. No intestino delgado, a digestibilidade máxima da MS de 34,89\% foi estimada com 49,01\% de concentrado na dieta; a digestibilidade da MO aumentou linearmente e as digestibilidades da PB, FDN, EE e CHOT não foram influenciadas pela inclusão de concentrado na dieta. Não houve efeito dos níveis de concentrado sobre as digestibilidades no intestino grosso para MS, MO, PB, EE e CHOT, cujas médias foram 17,$98 ; 12,48 ; 10,53 ;-2,84$ e $11,08 \%$, respectivamente.

Palavras-chave: consumo, digestibilidade parcial, digestibilidade total, nível de concentrado

\section{Intake and Total and Partial Apparent Nutrients Digestibilities in Bullos Fed Diets Containing Different Concentrate Levels}

\begin{abstract}
It was aimed to study the intake and total and partial nutrients digestibilities in bovine. It were used five $165 \mathrm{~kg}$ growing Nelore bulls, rumen, abomasum and ileum fistulated. A randomized blocks design with four treatments and five collection periods was used. The treatments consisted of four concentrate levels (20, 40, 60 and 80\%). The roughage used was Tifton 85' Bermuda grass hay (Cynodon dactylon (L.) Pers.). The NDF and ADF intakes only presented linear reduction with the increase of the concentrate level in the diet. DM and TND intakes were, in average, of 3.45 and $2.24 \mathrm{~kg} /$ day, respectively. The DM, OM and TCHO apparent digestibilities increased linearly, in function of the concentrate level in the diet. CP and EE apparent digestibilities presented averages of 59.50 and $70.81 \%$, respectively. There was a linear reduction in the NDF and ADF digestibilities. The concentrate level did not influence the CP and EE ruminal digestion, with averages of 4.80 and $1.41 \%$, respectively. The NDF ruminal digestibility showed linear reduction as the the concentrate level in the diet increased. In the small intestine, the maximum DM digestibility of $34.89 \%$ were estimated with $49.01 \%$ of concentrate in the diet, OM digestibility linearly increased and CP, NDF, EE and TCHO digestibilities were not influenced by the concentrate inclusion in the diet. There was not effect of the concentrate levels on the DM, OM, CP, EE and TCHO digestibilities in the large intestine, and your averages were $17.98,12.48,10.53,-2.84$ and $11.08 \%$, respectively.
\end{abstract}

Key Words: concentrate level, intake, partial digestibility, total digestibility

\section{Introdução}

O consumo e a digestibilidade afetam grandemente o desempenho animal, sendo a ingestão dos nutrientes digestíveis totais o fator mais importante. Com o aumento do nível de concentrado, espera-se aumento na digestibilidade e no consumo de matéria seca. O NRC (1984) prediz o consumo de MS a partir da concentração de energia líquida de mantença da ração, enquanto Mertens (1992) considerou as exigências energéticas dos animais e a capacidade de enchimento ruminal, ao apresentar equações para estimar o consumo.

\footnotetext{
1 Parte da tese de Doutorado do primeiro autor apresentada à UFV.

2 Professor da Universidade Católica Dom Bosco - UCDB, Campo Grande, MS. E.mail: itavo@ucdb.br

${ }^{3}$ Professores da UFV, Viçosa, MG. E.mail: scvfilho@ufv.br

${ }^{4}$ Professor da UESB, Itapetinga, BA. E.mail: ffsilva@uesb.br

5 Zootecnista - UFV. E.mail: ccbf itavo@msn.com

${ }^{6}$ Estudante de Mestrado - UFV.
} 
O conhecimento dos locais de digestão dos nutrientes é importante, pois permite calcular as quantidades aparentemente absorvidas dos mesmos nos diferentes segmentos do trato digestivo. Segundo Russell et al. (1992), o crescimento microbiano máximo é de 0,4 gramas de MS microbiana por grama de carboidrato degradado no rúmen. Este fato possibilita estimar as quantidades de compostos nitrogenados não-degradados no rúmen, os quais deverão ser adicionados às dietas com a finalidade de atender as exigências de proteína metabolizável dos animais.

Portanto, torna-se fundamental conhecer, além da produção de proteína microbiana, as quantidades de carboidratos totais degradados no rúmen. Valadares Filho (1995) calculou que $75 \%$ dos carboidratos totais digestíveis são degradados no rúmen. Contudo, a maioria dos dados desta revisão foi obtida a partir de experimentos com vacas em lactação. Também, neste trabalho, foi estimada uma eficiência microbiana média de 483,9 $\mathrm{g}$ de MS bacteriana/kg de carboidratos degradados no rúmen, valor superior ao sugerido por Russell et al. (1992).

Cardoso et al. (2000), avaliando níveis de concentrado em dietas de bovinos de corte sobre o consumo, a digestibilidade e o crescimento microbiano, observaram que o incremento nos níveis de concentrado resultou em aumentos lineares nas digestibilidades totais dos nutrientes, com exceção da digestibilidade total da FDN, que não foi influenciada pelo nível de concentrado. Entretanto, o aumento dos níveis de concentrado nas rações não alterou os locais de digestão dos nutrientes e o crescimento microbiano. Tais resultados foram similares aos encontrados por Dias et al. (2000), que também registraram aumentos lineares da digestibilidade aparente total com o aumento do nível de concentrado na dieta de bovinos de corte.

Todavia, o estudo de locais de digestão feito por Valadares Filho (1985) calculou que aproximadamente $58 \%$ da fração digestível da matéria seca é degradada no rúmen. Com relação aos locais de digestão da energia, Valadares Filho et al. (1987), trabalhando com ovinos, apresentaram que do total digestível, aproximadamente $60 \%$ foi digerido antes do intestino delgado, $35 \%$ no intestino delgado e apenas $5 \%$ no intestino grosso.

Segundo Berchielli (1994), ao se aumentar o nível de concentrado da ração, haverá redução da digestão ruminal e, conseqüentemente, aumento na digestão intestinal da matéria seca. Isto ocorre devido à maior taxa de passagem promovida pelos maiores níveis de concentrado. Entretanto, Poore et al. (1990) observaram aumento na digestibilidade total da MS, quando se elevou o nível de concentrado na ração, mas isto não influenciou a digestibilidade da porção fibrosa das dietas. De acordo com Carvalho et al. (1997), não há efeito dos níveis de concentrado nas rações para as digestibilidades de matéria seca, proteína bruta, extrato etéreo, fibra em detergente neutro e carboidratos totais no intestino delgado. Cardoso et al. (2000) observaram que o aumento do nível de concentrado nas rações não alterou o local de digestão dos nutrientes.

Dessa forma, objetivou-se com este experimento avaliar o consumo e as digestibilidades aparentes totais e parciais em novilhos Nelore alimentados com rações contendo 20, 40, 60 e $80 \%$ de concentrado na dieta.

\section{Material e Métodos}

O experimento foi conduzido no Laboratório de Animais e no Laboratório de Nutrição Animal do Departamento de Zootecnia da Universidade Federal de Viçosa, em Viçosa, MG.

A fibra em detergente ácido indigestível (FDAi) foi utilizada como indicador interno para estimar a produção fecal e os fluxos de MS nos compartimentos do trato gastrintestinal, para posterior determinação das digestibilidades aparentes total e parcial dos nutrientes. Foram utilizados cinco novilhos Nelore, não-castrados, com idade de 8 meses e peso inicial médio de $165 \mathrm{~kg}$, fistulados no rúmen, abomaso e íleo, segundo as técnicas descritas por Leão \& Coelho da Silva (1980). Os animais foram mantidos em regime de confinamento, alojados em baias individuais cobertas, com piso de concreto revestido de borracha, de $3 \times 3 \mathrm{~m}$ de área, dotadas de comedouros de alvenaria e bebedouros individuais.

O delineamento utilizado foi em blocos casualizados, em cinco períodos experimentais, com cinco animais e quatro tratamentos. Em todos os cincos períodos experimentais um tratamento possuía dois animais, de forma que todos os animais passaram por todos os tratamentos utilizados. Utilizaram-se quatro tratamentos sendo constituídos de feno de capim-Tifton 85 (Cynodon dactylon (L.) Pers.) triturado e mistura concentrada, que constituiu 20,40, 60 e $80 \%$ da ração total (Tabelas 1, 2 e 3). As rações, balanceadas de acordo com o NRC (1996), foram isoprotéicas ( $15 \%$ de $\mathrm{PB})$ e apresentaram aproxima-

R. Bras. Zootec., v.31, n.3, p.1543-1552, 2002 (suplemento) 
Tabela 1 - Proporção dos ingredientes nos concentrados, na base da matéria natural Table 1 - Proportion of the ingredients in the concentrates, on as fed basis

\begin{tabular}{|c|c|c|c|c|}
\hline \multirow[t]{2}{*}{$\begin{array}{l}\text { Ingredientes } \\
\text { Ingredients }\end{array}$} & \multicolumn{4}{|c|}{$\begin{array}{l}\text { Nível de concentrado na dieta (\%) } \\
\text { Concentrate level in the diet (\%) }\end{array}$} \\
\hline & 20 & 40 & 60 & 80 \\
\hline Fubá de milho (\%) & 88,72 & 91,96 & 93,05 & 95,37 \\
\hline $\begin{array}{l}\text { Corn starch (\%) } \\
\text { Farelo de soja (\%) } \\
\text { Sovbean meal (\%) }\end{array}$ & 4,75 & 4,38 & 4,03 & 1,75 \\
\hline $\begin{array}{l}\text { Uréia (\%) } \\
\text { Urea (\%) }\end{array}$ & 2,93 & 1,57 & 1,16 & 1,25 \\
\hline $\begin{array}{l}\text { Calcário calcítico }(\%) \\
\text { Calcite limestone (\%) }\end{array}$ & 0,05 & 0,54 & 0,88 & 1,04 \\
\hline $\begin{array}{l}\text { Fosfato bicálcico (\%) } \\
\text { Dicalcium phosphate (\%) }\end{array}$ & 2,78 & 1,12 & 0,57 & 0,33 \\
\hline $\begin{array}{l}\text { Sal comum }(\%) \\
\text { Salt }(\%)\end{array}$ & 0,70 & 0,38 & 0,28 & 0,23 \\
\hline $\begin{array}{l}\text { Sulfato de zinco }(\mathrm{g} / 100 \mathrm{~kg}) \\
\text { Zinc sulfate }(\mathrm{g} / 100 \mathrm{~kg})\end{array}$ & 67,20 & 33,60 & 22,40 & 16,80 \\
\hline $\begin{array}{l}\text { Sulfato de cobre }(\mathrm{g} / 100 \mathrm{~kg}) \\
\text { Cupper sulfate }(\mathrm{g} / 100 \mathrm{~kg})\end{array}$ & 16,00 & 8,00 & 5,32 & 4,00 \\
\hline $\begin{array}{l}\text { Sulfato de cobalto }(\mathrm{g} / 100 \mathrm{~kg}) \\
\text { Cobalt sulfate }(\mathrm{g} / 100 \mathrm{~kg})\end{array}$ & 0,21 & 0,10 & 0,07 & 0,05 \\
\hline $\begin{array}{l}\text { Iodato de potássio }(\mathrm{g} / 100 \mathrm{~kg}) \\
\text { Potassium iodate }(\mathrm{g} / 100 \mathrm{~kg})\end{array}$ & 0,42 & 0,21 & 0,14 & 0,11 \\
\hline $\begin{array}{l}\text { Selenito de sódio }(\mathrm{g} / 100 \mathrm{~kg}) \\
\text { Sodium selenite }(\mathrm{g} / 100 \mathrm{~kg})\end{array}$ & 0,21 & 0,11 & 0,07 & 0,05 \\
\hline
\end{tabular}

damente $32 \%$ da PB na forma de compostos nitrogenados não-protéicos.

Os períodos experimentais tiveram duração de 21 dias cada, sendo 10 dias de adaptação à dieta e 11 dias para as coletas de fezes e digesta de abomaso e íleo, além de urina, conteúdo ruminal para isolamento de bactérias e $\mathrm{N}$-amoniacal. Os animais foram pesa- dos no início e ao final de cada período experimental.

A ração total misturada foi fornecida à vontade, em uma única vez ao dia, às $7 \mathrm{~h} 30$, sendo as sobras recolhidas e pesadas diariamente, para determinação do consumo diário. A quantidade de ração fornecida foi calculada de modo que permitiu $10 \%$ de sobras, ao passo que a água foi fornecida à vontade. Para os

Tabela 2 - Teores médios de matéria seca (MS), matéria orgânica (MO), proteína bruta (PB), extrato etéreo (EE), fibra em detergente neutro (FDN), carboidratos não-fibrosos (CNF), cálcio (Ca) e fósforo $(P)$ dos concentrados e do feno

Table 2 - Average contents of dry matter (DM), organic matter (OM), crude protein (CP), ether extract (EE), neutral detergent fiber $(N D F)$, non fiber carbohydrates (NFC), calcium (Ca) and phosphorus ( $P$ ) of concentrates and hay

\begin{tabular}{|c|c|c|c|c|c|}
\hline \multirow[t]{2}{*}{ Itens } & \multirow[t]{2}{*}{$\begin{array}{c}\text { Feno } \\
\text { Hay }\end{array}$} & \multicolumn{4}{|c|}{$\begin{array}{l}\text { Nível de concentrado na dieta }(\%) \\
\text { Concentrate level in the diet }(\%)\end{array}$} \\
\hline & & 20 & 40 & 60 & 80 \\
\hline $\operatorname{MS}(D M)(\%)$ & 88,55 & 87,30 & 87,29 & 87,33 & 88,55 \\
\hline $\mathrm{MO}(O M)^{1}$ & 94,18 & 95,77 & 96,37 & 97,02 & 96,55 \\
\hline $\mathrm{PB}(C P)^{1}$ & 14,09 & 21,98 & 16,62 & 15,78 & 14,63 \\
\hline $\mathrm{EE}^{1}$ & 1,93 & 2,78 & 4,30 & 2,66 & 1,89 \\
\hline FDN $(N D F)^{1,2}$ & 74,47 & 14,01 & 9,86 & 13,53 & 13,81 \\
\hline $\mathrm{CNF}(N F C)^{1}$ & 3,69 & 57,00 & 65,59 & 65,05 & 66,22 \\
\hline $\mathrm{Ca}^{1}$ & 0,36 & 0,96 & 0,70 & 0,71 & 0,84 \\
\hline $\mathrm{P}^{1}$ & 0,20 & 0,95 & 0,48 & 0,40 & 0,50 \\
\hline
\end{tabular}

$1 \%$ na matéria seca (\% in dry matter).

2 FDN corrigida para cinzas e proteína (NDF corrected for ash and protein).

R. Bras. Zootec., v.31, n.3, p.1543-1552, 2002 (suplemento) 
Tabela 3 - Teores médios de matéria seca (MS), matéria orgânica (MO), proteína bruta (PB), extrato etéreo (EE), fibra em detergente neutro (FDN), carboidratos não-fibrosos (CNF), nutrientes digestíveis totais (NDT), cálcio (Ca) e fósforo $(P)$ das dietas experimentais

Table 3 - Average contents of dry matter (DM), organic matter (OM), crude protein (CP), ether extract (EE), neutral detergent fiber (NDF), non fiber carbohydrates (NFC), total digestible nutrients (TDN), calcium (Ca) and phosphorus (P) of the experimental diets

\begin{tabular}{|c|c|c|c|c|}
\hline \multirow[t]{2}{*}{$\begin{array}{l}\text { Ingredientes } \\
\text { Ingredients }\end{array}$} & \multicolumn{4}{|c|}{$\begin{array}{l}\text { Nível de concentrado na dieta }(\%) \\
\text { Concentrate level in the diet }(\%)\end{array}$} \\
\hline & 20 & 40 & 60 & 80 \\
\hline $\mathrm{MS}(D M), \%$ & 88,21 & 88,05 & 87,79 & 87,58 \\
\hline $\mathrm{MO}(O M)^{1}$ & 94,50 & 95,06 & 95,88 & 96,08 \\
\hline $\mathrm{PB}(C P)^{1}$ & 15,67 & 15,10 & 15,11 & 14,52 \\
\hline $\mathrm{EE}^{1}$ & 2,30 & 3,03 & 2,46 & 1,95 \\
\hline FDN $(N D F)^{1,2}$ & 62,37 & 48,62 & 37,90 & 25,94 \\
\hline $\mathrm{CNF}(N F C)^{1}$ & 14,16 & 28,31 & 40,41 & 53,67 \\
\hline $\mathrm{Ca}^{1}$ & 0,48 & 0,50 & 0,57 & 0,74 \\
\hline $\mathrm{P}^{1}$ & 0,35 & 0,31 & 0,32 & 0,44 \\
\hline
\end{tabular}

$1 \%$ na matéria seca (\% in dry matter).

2 FDN corrigida para cinzas e proteína (NDF corrected for ash and protein).

tratamentos com 60 e $80 \%$ de concentrado, foram fornecidos $50 \mathrm{~g}$ de bicarbonato de sódio por dia, adicionados à ração total.

Foram realizadas amostras compostas do feno fornecido, dos concentrados, por tratamento, e das sobras, por animal em cada período. Todas estas amostras foram devidamente armazenadas $\mathrm{a}-15^{\circ} \mathrm{C}$, posteriormente moídas em moinho com peneira de 1 mm e submetidas às análises laboratoriais.

As coletas de fezes e digestas de abomaso e de íleo foram feitas uma vez ao dia, seguindo a metodologia de coleta de dois dias, sugerida por Ítavo (2001). No dia um, às $10 \mathrm{~h}$, procedeu-se à primeira coleta e no dia dois, às $16 \mathrm{~h}$, à segunda. As amostras de fezes e de digesta de abomaso e íleo acondicionadas em recipientes de vidro tipo pirex e devidamente identificadas, foram pré-secas em estufa de ventilação forçada, a $65^{\circ} \mathrm{C}$ por 96 horas, e processadas em moinho com peneira de $1 \mathrm{~mm}$. Finalmente, foi elaborada uma amostra composta por animal, com base no peso seco, amostrando-se $100 \mathrm{~g}$ por coleta em cada animal. As amostras compostas foram devidamente acondicionadas em recipientes de vidro e, posteriormente, submetidas às análises laboratoriais.

Para determinação do indicador interno, fibra em detergente ácido indigestível (FDAi), foram incubados no rúmen os alimentos, as sobras, as fezes e as digestas de abomaso e íleo, por 144 horas, tendo o resíduo sido assumido como indigestível.
Os teores de matéria seca (MS), matéria orgânica $(\mathrm{MO})$, proteína bruta $(\mathrm{PB})$, extrato etéreo $(\mathrm{EE})$, fibra em detergente neutro (FDN) e fibra em detergente ácido (FDA) e a dosagem de nitrogênio total foram determinados em todas as amostras, conforme técnicas descritas por Silva (1990).

Os carboidratos totais (CHOT) foram obtidos por intermédio da equação: $100-(\% \mathrm{~PB}+\% \mathrm{EE}+\%$ Cinzas $)$ (Sniffen et al., 1992), enquanto os carboidratos nãofibrosos (CNF), pela diferença entre CHOT e FDN. Os teores de nutrientes digestíveis totais (NDT) e energia metabolizável foram obtidos conforme recomendações de Sniffen et al. (1992), sendo NDT= $(\mathrm{PBD}+\mathrm{CHOTD})+2,25$ (EED), em que PBD, CHOTD e EED significam, respectivamente, consumos de $\mathrm{PB}$, CHOT e EE digestíveis. Para a energia metabolizável considerou-se que $1 \mathrm{~kg}$ de NDT equivale 4,409 Mcal de energia digestível e para a transformação em energia metabolizável utilizou-se o valor de $82 \%$ de eficiência de utilização de energia digestível.

As variáveis estudadas, consumo e digestibilidade dos nutrientes, foram avaliadas por meio de análise de variância e as diferenças estatísticas pelo teste $\mathrm{F}$ em nível de 5\%, utilizando-se o Sistema de Análises Estatísticas e Genéticas SAEG (UFV/CPD, 1997). Os modelos foram escolhidos com bases na significância dos coeficientes de regressão utilizando-se o teste $\mathrm{F}$, adotando $10 \%$ de probabilidade, no coeficiente de determinação e no fenômeno estudado. 


\section{Resultados e Discussão}

As médias, coeficientes de variação e equações de regressão ajustadas para os consumos de nutrientes, em kg/dia, e os consumos de MS e FDN em porcentagem do peso $(\% \mathrm{PV})$, em bovinos Nelore fistulados, estão apresentados na Tabela 4. Somente os consumos de FDN e FDA decresceram linearmente, inversamente influenciados $(\mathrm{P}<0,05)$ pelos níveis de concentrado das dietas.

A média de consumo de MS para as dietas foi de $3,45 \mathrm{~kg} /$ dia. O consumo de nutrientes digestíveis totais (CNDT) não foi influenciado pelo nível de concentrado das dietas, sugerindo que o feno utilizado proporcionou alta quantidade de nutrientes digestíveis, em média $2,24 \mathrm{~kg} /$ dia. Ao se observarem as exigências de energia para mantença para animais Nelore, apontadas por Silva (2001), tem-se 1,34 kg/dia de NDT para animais com $200 \mathrm{~kg}$ de PV e $3,00 \mathrm{~kg} /$ dia de NDT para ganho de $0,70 \mathrm{~kg} / \mathrm{dia}$. Tal fato sugere que as dietas experimentais (Tabela 4) supriram as exigências de mantença dos animais.

Há de se destacar que o consumo de fibra em detergente neutro (CFDN) foi maior que 1,2\% PV para os níveis 20 e $40 \%$ de concentrado. Mertens (1992) relatou que, para vacas de leite, consumos acima deste valor seriam regulados por mecanismos físicos, para dieta total misturada.

As médias e equações de regressão ajustadas para digestibilidade aparente dos nutrientes estão apresentadas na Tabela 5. Os coeficientes de digestibilidade aparente da MS, MO e CHOT aumentaram linearmente, em função do nível de concentrado na dieta. Entretanto, os coeficientes de digestibilidade aparente da PB e EE não sofreram influência do nível de concentrado, apresentando média de 59,50 e $70,81 \%$, respectivamente. Da mesma forma, Carvalho et al. (1997) não encontraram efeito do nível de concentrado

Tabela 4 - Médias, coeficientes de variação e equações de regressão ajustadas para o consumo de nutrientes (kg/dia) e consumo de MS e FDN em porcentagem do peso (\%PV) em bovinos Nelore, em função do nível (n) de concentrado na dieta e respectivos coeficientes de determinação

Table 4 - Means, coefficients of variation and fitted regression equations for the nutrients intake (kg/day) and DM and NDF intake $(\% L W)$, on the concentrate level ( $n)$ of the diets fed Nellore bulls, and the respective coefficients of determination

\begin{tabular}{|c|c|c|c|c|c|}
\hline \multirow[t]{2}{*}{$\begin{array}{l}\text { Variáveis } \\
\text { Variables }\end{array}$} & \multicolumn{4}{|c|}{$\begin{array}{c}\text { Nível de concentrado (\%) } \\
\text { Concentrate level (\%) }\end{array}$} & \multirow[t]{2}{*}{$\mathrm{CV}(\%)$} \\
\hline & 20 & 40 & 60 & 80 & \\
\hline $\begin{array}{l}\mathrm{CMS}^{1}(\mathrm{~kg} / \mathrm{dia}) \\
D M I \text { (kg/day) }\end{array}$ & 3,48 & 3,82 & 3,63 & 3,03 & 25,63 \\
\hline $\begin{array}{l}\mathrm{CMS}^{2}(\% \mathrm{PV}) \\
D M I(\% L W)\end{array}$ & 2,02 & 2,15 & 2,15 & 1,80 & 25,27 \\
\hline $\begin{array}{l}\mathrm{CMO}^{3}(\mathrm{~kg} / \mathrm{dia}) \\
O M I(\mathrm{~kg} / \text { day })\end{array}$ & 3,31 & 3,65 & 3,51 & 2,93 & 25,82 \\
\hline $\begin{array}{l}\mathrm{CPB}^{4}(\mathrm{~kg} / \mathrm{dia}) \\
C P I(\mathrm{~kg} / \text { day })\end{array}$ & 0,47 & 0,49 & 0,47 & 0,36 & 28,69 \\
\hline $\begin{array}{l}\mathrm{CEE}^{5}(\mathrm{~kg} / \mathrm{dia}) \\
\text { EEI ( } \mathrm{kg} / \text { day })\end{array}$ & 0,08 & 0,12 & 0,08 & 0,05 & 41,55 \\
\hline $\begin{array}{l}\mathrm{CFDN}^{6}(\mathrm{~kg} / \mathrm{dia}) \\
N D F I(\mathrm{~kg} / \text { day })\end{array}$ & 2,62 & 2,29 & 1,68 & 0,98 & 7,67 \\
\hline $\begin{array}{l}\mathrm{CFDN}^{7}(\% \mathrm{PV}) \\
N D F I(\% L W)\end{array}$ & 1,53 & 1,30 & 0,99 & 0,59 & 7,10 \\
\hline $\begin{array}{l}\mathrm{CFDA}^{8}(\mathrm{~kg} / \mathrm{dia}) \\
A D F I(\mathrm{~kg} / \text { day })\end{array}$ & 1,23 & 1,05 & 0,72 & 0,39 & 7,70 \\
\hline $\begin{array}{l}\operatorname{CNDT}^{9}(\mathrm{~kg} / \mathrm{dia}) \\
T D N I(\mathrm{~kg} / \text { day })\end{array}$ & 2,00 & 2,46 & 2,44 & 2,13 & 26,40 \\
\hline
\end{tabular}

CMS = consumo de matéria seca $\mathrm{CMO}=$ consumo de matéria orgânica; $\mathrm{CPB}=$ consumo de proteína bruta; $\mathrm{CEE}=$ consumo de extrato etéreo; CFDN = consumo de fibra em detergente neutro, CFDA = consumo de fibra em detergente ácido; CNDT = consumo de nutrientes digestíveis totais; $\mathrm{CV}=$ coeficiente de variação.

*** Significância das equações de regressão $(P<0,10)$.

$D M I=$ dry matter intake, OMI = organic matter intake; $C P I=$ crude protein intake; EEI = ether extract intake, NDFI = neutral detergent fiber intake, ADFI = acid detergent fiber intake; TDNI = total digestible nutrients intake; $C V=$ coefficient of variation.

*** Significance of the regression equations $(P<.10)$.

$1 \mathrm{Y}=3,45 ;{ }^{2} \mathrm{Y}=2,01 ;{ }^{3} \mathrm{Y}=3,31 ;{ }^{4} \mathrm{Y}=0,44 ;{ }^{5} \mathrm{Y}=0,078 ; 6 \mathrm{Y}=3,24627-0,0273063^{* * *} \mathrm{n}\left(\mathrm{R}^{2}=0,98\right) ;{ }^{2} \mathrm{Y}=1,86711-0,891498^{* * *} \mathrm{n}$ $\left(R^{2}=0,98\right) ;{ }^{8} Y=1,54226-0,0140290^{* * *} n\left(R^{2}=0,98\right) ; 9^{9} Y=2,24$. 
Tabela 5 - Médias e equações de regressão ajustadas para digestibilidades aparentes totais de nutrientes em bovinos Nelore, em função do nível (n) de concentrado na dieta, e respectivos coeficientes de determinação

Table 5 - Means and fitted regression equations for nutrients total apparent digestibilities (\%), on the level of concentrate (n) of the diets fed Nellore bulls, and the respective coefficients of determination

\begin{tabular}{|c|c|c|c|c|}
\hline \multirow[t]{2}{*}{$\begin{array}{l}\text { Ingredientes } \\
\text { Ingredients }\end{array}$} & \multicolumn{4}{|c|}{$\begin{array}{l}\text { Nível de concentrado na dieta }(\%) \\
\text { Concentrate level in the diet }(\%)\end{array}$} \\
\hline & 20 & 40 & 60 & 80 \\
\hline $\operatorname{MS}(D M)^{1}$ & 56,57 & 61,15 & 66,94 & 72,94 \\
\hline $\mathrm{MO}(O M)^{2}$ & 59,30 & 63,19 & 68,90 & 74,48 \\
\hline $\mathrm{PB}(C P)^{3}$ & 58,72 & 58,61 & 58,73 & 63,86 \\
\hline $\mathrm{EE}^{4}$ & 67,42 & 71,41 & 72,35 & 70,85 \\
\hline CHOT $(T C H O)^{5}$ & 59,67 & 63,70 & 69,81 & 75,47 \\
\hline FDN $(N D F)^{6}$ & 82,52 & 80,34 & 77,90 & 73,26 \\
\hline FDA $(A D F)^{7}$ & 64,35 & 58,99 & 48,90 & 48,70 \\
\hline
\end{tabular}

$\mathrm{MS}$ = matéria seca; $\mathrm{MO}=$ matéria orgânica; $\mathrm{PB}$ = proteína bruta; $\mathrm{EE}=$ extrato etéreo; $\mathrm{CHOT}=$ carboidratos totais; FDN = fibra em detergente neutro; FDA = fibra em detergente ácido.

*** Significância das equações de regressão $(P<0,10)$.

$D M=$ dry matter; $O M=$ organic matter; $C P=$ crude protein; $E E=$ ether extract; $T C H O=$ total carbohydrates, $N D F=$ neutral detergent fiber; $A D F=$ acid detergent fiber.

*** Significance of the regression equations $(P<, 10)$.

${ }^{1} Y=53,5338+0,186676^{* *} n\left(R^{2}=0,99\right) ;{ }^{2} Y=56,1439+0,180363^{* * *} n\left(R^{2}=0,99\right) ;{ }^{3} Y=59,50 ;{ }^{4} Y=70,81 ;{ }^{5} Y=55,6020+0,212509^{* * *} n$ $\left(R^{2}=0,99\right) ;{ }^{6} \mathrm{Y}=87,6203-0,201175^{\star \star *} \mathrm{n}\left(\mathrm{R}^{2}=0,96\right) ;{ }^{7} \mathrm{Y}=70,1894-0,305134^{\star \star \star} \mathrm{n}\left(\mathrm{R}^{2}=0,91\right)$

sobre os coeficientes de digestibilidade da PB e EE, com média de 63,5 e $79,9 \%$, respectivamente. Porém, observaram efeito quadrático para os coeficientes de digestibilidade aparente da MS, MO e CHOT e concluíram que o nível de concentrado em que foram obtidos os maiores coeficientes de digestibilidade aparente foi próximo a $40 \%$.

Cardoso et al. (2000) observaram que o incremento nos níveis de concentrado resultou em aumentos lineares nas digestibilidades totais dos nutrientes, com exceção da digestibilidade aparente da FDN, que não sofreu influência do nível de concentrado. Dias et al. (2000) também relataram acréscimos lineares da digestibilidade aparente total com o aumento do nível de concentrado na dieta de bovinos de corte.

Houve redução linear $(\mathrm{P}<0,05)$ nos coeficientes de digestibilidade aparente da FDN e FDA com o aumento dos níveis de concentrado das dietas. Este fato pode ser explicado por um mecanismo de competição entre bactérias amilolíticas e fibrolíticas, como citado por Olson et al. (1999). Esses autores propuseram que os microrganismos amilolíticos se desenvolvem mais rapidamente do que os fibrolíticos, pois os amilolíticos apresentam uma vantagem competitiva quanto ao uso do nitrogênio para seu rápido crescimento, limitando a disponibilidade de nitrogênio para os microrganismos celulolíticos. O aumento de quantidades de carboidratos rapidamente

R. Bras. Zootec., v.31, n.3, p.1543-1552, 2002 (suplemento) fermentáveis no rúmen iria fortalecer esta competição. Estes relatos confirmam as citações de Russell (1998), o qual notou que o excesso de carboidratos, na presença de quantidades inadequadas de compostos nitrogenados, poderia ter efeitos negativos no crescimento microbiano, principalmente microrganismos celulolíticos.

As médias para digestibilidades parciais dos nutrientes, em função do nível de concentrado da dieta, e suas respectivas equações de regressão estão apresentadas na Tabela 6 . O nível de concentrado influenciou significativamente $(\mathrm{P}<0,10)$ a digestibilidade ruminal da MS, MO e CHOT, estimando-se digestibilidades mínimas com 51,15; 51,23; e $49,58 \%$ de concentrados, respectivamente.

O nível de concentrado reduziu significativamente $(\mathrm{P}<0,10)$ a digestão ruminal da porção fibrosa e não afetou significativamente $(\mathrm{P}<0,10)$ a digestão ruminal da proteína e extrato etéreo, com médias de 4,80 e $1,41 \%$ do consumido, respectivamente. Dias et al. (2000) encontraram resultados contraditórios aos apresentados na Tabela 6 , sendo que seus valores para digestão ruminal da PB e EE foram negativos. Porém, para a digestibilidade ruminal da MS, os níveis de concentrado não apresentaram efeito significativo, ficando em média $57,48 \%$, valor próximo à média observada neste experimento. Também Valadares Filho (1985), avaliando digestibilidade ruminal da MS, utilizando 40 e $60 \%$ de concentrado na dieta de 
novilhos, observou maior valor $(56,6 \%)$ para o nível mais alto de concentrado.

Segundo Elizalde et al. (1999), a digestão ruminal da MO não foi afetada pela inclusão de milho na dieta de novilhos. Também Berchielli (1994) e Dutra et al. (1997) verificaram variação na digestão ruminal da $\mathrm{MO}$, em função do concentrado da dieta. Enquanto Bürger et al. (2000) apresentaram valores para a digestibilidade ruminal da MO decrescentes linearmente com o aumento do nível de concentrado.

A média do coeficiente de digestibilidade ruminal da PB foi $4,80 \%$, não sendo afetado pelo nível de concentrado. Resultados maiores foram obtidos por Rabello (1995), apresentando 20,4\% para vacas leiteiras e por Carvalho et al. (1997), que apresentaram valor médio de $18,02 \%$. Estes autores sugeriram que os valores positivos estariam indicando uma absorção de amônia no rúmen, podendo assim ter ocorrido perda de proteína dietética. Todavia, tal fato pode significar que a quantidade de PB das dietas foi suficiente para suprir as exigências dos microrganismos ruminais, sendo que resultados contrários foram obtidos por Ladeira et al. (1999).

A média da digestibilidade ruminal do EE foi $1,41 \%$. Valores de digestão ruminal do EE negativos ou próximos de zero seriam esperados, pois não há microrganismo ruminal capaz de utilizar lipídios como fonte energética. Resultados semelhantes ao deste trabalho foram encontrados por Carvalho et al. (1997), que encontraram valor médio de $8,85 \%$, indicando que não houve síntese de lipídios microbianos. Contrariamente, Ladeira et al. (1999) observaram efeito quadrático do nível de concentrado sobre a digestibilidade ruminal do EE e sugeriram que os valores negativos para digestão ruminal de EE podem ser conseqüência da síntese de lipídios microbianos.

A digestibilidade ruminal da FDN apresentou redução linear com o aumento do nível de concentrado na dieta, o que indica que a quantidade crescente de concentrado influenciou a digestão da fibra das rações. Tal resultado também foi observado por Poore et al. (1990), que utilizando $90 \%$ de concentrado, apontaram redução na digestibilidade ruminal da FDN. Ladeira et al. (1999) também apresentaram resultados de redução linear da digestibilidade ruminal da FDN. Os autores atribuíram isto à acidificação do pH ruminal, em função dos níveis crescentes de concentrado na dieta. Todavia, neste experimento, nos tratamentos com 60 e $80 \%$ de concentrado, foi acrescentado bicarbonato para que não ocorresse tal evento. Contrariamente, Berchielli (1994), Carvalho et al. (1997) e Bürger et al. (2000) não encontraram efeito do nível de concentrado sobre a digestão ruminal da FDN. Também Elizalde et al. (1999) não observaram efeito dos crescentes níveis de milho na dieta sobre a digestão ruminal da fibra.

No intestino delgado, estimou-se a digestibilidade máxima da MS em 34,89\% com $49,01 \%$ de concentrado na dieta. Já a digestibilidade da MO aumentou linearmente com o incremento do nível de concentrado e as digestibilidades de PB, FDN, EE e CHOT não foram influenciadas pela inclusão de concentrado nas dietas.

Dias et al. (2000) encontraram comportamento quadrático para a digestibilidade da MS no intestino delgado, a exemplo do constatado neste trabalho. Por sua vez, Berchielli (1994), Bürger et al. (2000) e Tibo et al. (2000) não verificaram efeito do nível de concentrado sobre a digestão intestinal da MS. Já Ladeira et al. (1999) observaram aumentos lineares da digestibilidade da MS e MO, em função de níveis crescentes de concentrado na dieta. A digestibilidade da MO no intestino delgado apresentou aumento linear, concordando com os resultados de Ladeira et al. (1999) e Tibo et al. (2000).

A digestibilidade da PB no intestino delgado não foi influenciada significativamente $(P>0,10)$ pela inclusão de concentrado na dieta, apresentando média de 53,73\%. Tal resultado está de acordo com Carvalho et al. (1997) e Cardoso et al. (2000), que encontraram 58,10 e $64,69 \%$, respectivamente. Tais valores são inferiores ao valor citado pelo NRC (1985) para a digestão de compostos nitrogenados no intestino delgado. Tibo et al. (2000) também não observaram efeito do nível de concentrado e apresentaram média de $65,30 \%$ para a digestibilidade intestinal total da PB. Entretanto, Ladeira et al. (1999) e Dias et al. (2000) encontraram efeito do nível de concentrado sobre a digestibilidade intestinal da $\mathrm{PB}$, apresentando aumentos lineares. O ARC (1984) e o NRC (1985) adotaram, respectivamente, 80 e $85 \%$ para a digestibilidade verdadeira de compostos nitrogenados não-amoniacais no intestino delgado.

A digestibilidade da FDN no intestino delgado não foi influenciada pelo concentrado da dieta e apresentou média de 12,43\% (Tabela 6). Bürger et al (2000) estudando consumo e digestibilidades parciais em bezerros holandeses alimentados com dietas contendo diferentes níveis de concentrado apresentou valo- 
res de 2,$76 ; 3,75$ e $22,64 \%$ para a digestibilidade intestinal da FDN, respectivamente para os níveis 30,75 e $90 \%$ de concentrado. Estes autores não encontraram influência do nível de concentrado sobre a digestibilidade da FDN. Cardoso et al. (2000) não verificaram efeito do nível de concentrado e apresentaram 16,27 e $8,60 \%$ de digestibilidade da FDN no intestino delgado para os níveis de 37,5 e $62,5 \%$ de concentrado. Valores negativos ou positivos de grande magnitude podem indicar um erro na estimativa de fluxo de MS, já que não há digestão de fibra nesse compartimento. Já Carvalho et al. (1997) observaram 0,21\% para a digestibilidade da FDN no intestino delgado. Tais relatos confir- mam a ausência de digestão da porção fibrosa nesse compartimento do trato gastrintestinal.

Não houve efeito dos níveis de concentrado sobre a digestibilidade no intestino grosso para a MS, MO, PB, EE e CHOT, e suas médias foram 17,$98 ; 12,48$; 5,$89 ;-2,84$ e $11,08 \%$, respectivamente. A digestibilidade da FDN no intestino grosso apresentou aumento linear em função do nível. Cardoso et al. (2000) não observaram efeito do nível de concentrado sobre as digestibilidades da MS, MO, PB, EE, FDN e CHOT, no intestino grosso. Também Carvalho et al. (1997) não verificaram efeito de inclusão de concentrado para MS, MO, PB, EE e FDN. Porém, CHOT e CNE apresentaram comportamento

Tabela 6 - Médias e equações de regressão ajustadas para digestibilidades parciais (\%) de nutrientes em bovinos Nelore, em função do nível ( $n$ ) de concentrado na dieta, e respectivos coeficientes de determinação

Table 6 - Means and fitted regression equations for partial nutrients digestibilities (\%), on the concentrate level (n) of the diets fed Nellore bulls, and the respective coefficients of determination

\begin{tabular}{|c|c|c|c|c|}
\hline \multirow[t]{2}{*}{$\begin{array}{l}\text { Variáveis } \\
\text { Variables }\end{array}$} & \multicolumn{4}{|c|}{$\begin{array}{l}\text { Nível de concentrado (\%) } \\
\text { Concentrate level (\%) }\end{array}$} \\
\hline & 20 & 40 & 60 & 80 \\
\hline & \multicolumn{4}{|c|}{$\begin{array}{l}\text { Digestibilidade ruminal } \\
\text { Ruminal digestibility }\end{array}$} \\
\hline $\operatorname{MS}(D M)^{1}$ & 61,93 & 54,30 & 48,32 & 61,25 \\
\hline $\mathrm{MO}(O M)^{2}$ & 64,01 & 61,76 & 54,87 & 69,32 \\
\hline $\mathrm{PB}(C P)^{3}$ & 10,63 & 4,74 & $-0,15$ & 2,80 \\
\hline $\mathrm{EE}^{4}$ & 4,26 & 6,05 & $-7,65$ & 2,98 \\
\hline $\mathrm{CHOT}(\mathrm{TCHO})^{5}$ & 73,63 & 67,43 & 63,71 & 80,69 \\
\hline \multirow[t]{2}{*}{$\operatorname{FDN}(N D F)^{6}$} & 89,38 & 81,95 & 70,99 & 67,60 \\
\hline & \multicolumn{4}{|c|}{$\begin{array}{l}\text { Digestibilidade no intestino delgado } \\
\text { Digestibility in the small intestine }\end{array}$} \\
\hline $\operatorname{MS}(D M)^{7}$ & 19,51 & 31,56 & 34,71 & 16,51 \\
\hline $\mathrm{MO}(O M)^{8}$ & 20,93 & 25,10 & 27,73 & 26,37 \\
\hline $\mathrm{PB}(C P)^{9}$ & 50,80 & 51,17 & 60,84 & 54,06 \\
\hline $\mathrm{EE}^{10}$ & 81,15 & 76,16 & 79,28 & 84,05 \\
\hline $\mathrm{CHOT}(\mathrm{TCHO})^{11}$ & 13,56 & 22,73 & 23,84 & 10,09 \\
\hline \multirow[t]{2}{*}{$\mathrm{FDN}(N D F)^{12}$} & 7,36 & 12,03 & 14,80 & 15,54 \\
\hline & \multicolumn{4}{|c|}{$\begin{array}{l}\text { Digestibilidade no intestino grosso } \\
\text { Digestibility in the large intestine }\end{array}$} \\
\hline $\operatorname{MS}(D M)^{13}$ & 18,56 & 14,14 & 16,97 & 22,24 \\
\hline $\mathrm{MO}(O M)^{14}$ & 15,06 & 13,14 & 17,40 & 4,31 \\
\hline $\mathrm{PB}(C P)^{15}$ & 3,48 & 11,66 & 22,69 & 8,53 \\
\hline $\mathrm{EE}^{16}$ & 0,47 & 15,19 & 18,46 & $-22,81$ \\
\hline $\mathrm{CHOT}(\mathrm{TCHO})^{17}$ & 12,81 & 9,84 & 12,45 & 9,22 \\
\hline FDN $(N D F)^{18}$ & 3,26 & 6,02 & 14,21 & 16,86 \\
\hline
\end{tabular}

$\mathrm{MS}=$ matéria seca; $\mathrm{MO}=$ matéria orgânica; $\mathrm{PB}=$ proteína bruta; $\mathrm{FDN}=$ fibra em detergente neutro; $\mathrm{EE}=$ extrato etéreo; $\mathrm{CHOT}=$ carboidratos totais.

*** Significância das equações de regressão $(P<0,10)$.

$D M=$ dry matter; $O M=$ organic matter; $C P=$ crude protein; $N D F=$ neutral detergent fiber; $E E=$ ether extract; $T C H O=$ total carbohydrates.

*** Significance of the regression equations $(P<.10)$.

$1 \mathrm{Y}=83,1976-1,29696^{* * *} \mathrm{n}+0,012678^{* * *} \mathrm{n}^{2}\left(\mathrm{R}^{2}=0,85\right) ;{ }^{2} \mathrm{Y}=92,3069-1,34644^{* * *} \mathrm{n}+0,0131402^{* * *} \mathrm{n}^{2}\left(\mathrm{R}^{2}=0,89\right) ;{ }^{3} \mathrm{Y}=4,80 ;$

${ }^{4} \mathrm{Y}=1,41 ; 5 \mathrm{Y}=98,0363-1,17888^{* * *} \mathrm{n}+0,0118879^{* * *} \mathrm{n}^{2}\left(\mathrm{R}^{2}=0,80\right) ;{ }^{6} \mathrm{Y}=96,5021-0,378649^{* * *} \mathrm{n}\left(\mathrm{R}^{2}=0,95\right) ; 7 \mathrm{Y}=-7,03958$

$+1,71123^{* * *} n-0,0174579^{* * *} n^{2}\left(R^{2}=0,84\right) ;{ }^{8} Y=24,8990+0,0640783^{* * *} n\left(R^{2}=0,81\right) ;{ }^{9} Y=53,73 ;{ }^{10} Y=81,81 ; 11 Y=17,56 ;$

$12 \mathrm{Y}=12,43 ;{ }^{13} \mathrm{Y}=17,98 ;{ }^{14} \mathrm{Y}=12,48 ;{ }^{15} \mathrm{Y}=10,53 ;{ }^{16} \mathrm{Y}=-2,84 ;{ }^{17} \mathrm{Y}=11,08 ;{ }^{18} \mathrm{Y}=-2,52033+0,254849^{* \star *} \mathrm{n}\left(\mathrm{R}^{2}=0,87\right)$

\section{R. Bras. Zootec., v.31, n.3, p.1543-1552, 2002 (suplemento)}


quadrático em função do nível de concentrado. Ainda, segundo Carvalho et al. (1997), os valores negativos para a digestão da PB no intestino grosso podem ter sido em razão da contribuição da síntese de proteína microbiana nesse local ou da secreção de $\mathrm{N}$ endógeno. Entretanto, tal fato não ocorreu neste experimento, em que a digestão média da PB neste compartimento foi positiva, $10,53 \%$ (Tabela 6 ).

A digestão da FDN no intestino grosso apresentou acréscimos lineares em função do aumento no nível de concentrado da dieta. Contrariamente, Ladeira et al. (1999) apontaram redução linear para a digestão da FDN neste compartimento do trato digestivo. No experimento de Bürger et al. (2000), a digestibilidade da FDN não foi influenciada pelo nível de concentrado na dieta de bezerros, apresentando média de 4,7\%. Da mesma forma, Dias et al. (2000) não encontraram efeito de nível de concentrado sobre a digestão da FDN, apresentando média maior, $21,77 \%$.

\section{Conclusões}

O consumo de NDT não sofreu influência do nível de concentrado.

O aumento do nível de concentrado não alterou o local de digestão dos nutrientes, porém a digestibilidade ruminal da FDN apresentou redução linear com o aumento do nível de concentrado na dieta.

\section{Literatura Citada}

AGRICULTURAL RESEARCH COUNCIL - ARC. Report of the protein group of the Agricultural Research Council Working Party, on the nutrient requirement of ruminants. London: Commonwealth Agricultural Bureaux, 1984. $45 \mathrm{p}$.

BERCHIELLI, T.T. Efeito da relação volumoso: concentrado sobre a partição da digestão, a síntese de proteína microbiana, produção de ácidos graxos voláteis e o desempenho de novilhos em confinamento. Belo Horizonte: Universidade Federal de Minas Gerais, 1994. 104p. Tese (Doutorado em Zootecnia) - Universidade Federal de Minas Gerais, 1994.

BÜRGER, P.J.; PEREIRA, J.C.; COELHO DA SILVA, J.F. et al. Consumo e digestibilidade aparente total e parcial em bezerros holandeses alimentados com dietas contendo diferentes níveis de concentrado. Revista Brasileira de Zootecnia, v.29, n.1, p.206-214, 2000.

CARDOSO, R.C., VALADARES FILHO, S.C., COELHO DA SILVA, J.F. et al. Consumo e digestibilidades aparentes totais e parciais de rações contendo diferentes níveis de concentrado, em novilhos F1 Limosin x Nelore. Revista Brasileira de Zootecnia, v.29, n.6, p.1832-1843, 2000.

CARVALHO, A.U.; VALADARES FILHO, S.C.; COELHO
DA SILVA, J.F. et al. Níveis de concentrado em dietas de zebuínos. 2. Coeficientes de digestibilidades aparentes parciais. Revista Brasileira de Zootecnia, v.26, n.5, p.9961006, 1997.

DIAS, H.L.C.; VALADARES FILHO, S.C.; COELHO DA SILVA, J.F. et al. Consumo e digestões totais e parciais em novilhos $\mathrm{F} 1$ limousin $\mathrm{x}$ nelore alimentados com dietas contendo cinco níveis de concentrado. Revista Brasileira de Zootecnia, v.29, n.2, p.545-554, 2000.

DUTRA, A.R.; QUEIROZ, A.C.; PEREIRA, J.C. et al. Efeito dos níveis de fibra e das fontes de proteínas sobre o consumo e digestão dos nutrientes em novilhos. Revista Brasileira de Zootecnia, v.26, n.4, p.787-796. 1997.

ELIZALDE, J.C.; MERCHEN, N.R.; FAULKNER, D.B. Supplemental cracked corn for steers fed fresh alfalfa: I. Effects on digestion of organic matter, fiber and starch. Journal of Animal Science, v.77, p.457-466, 1999.

ÍTAVO, L.C.V. Consumo, digestibilidade e eficiência microbiana de novilhos alimentados com dietas contendo vários níveis de concentrado, utilizando diferentes indicadores e períodos de coleta. Viçosa, MG: Universidade Federal de Viçosa, 2001. 100p. Tese (Doutorado em Zootecnia) - Universidade Federal de Viçosa, 2001.

LADEIRA, M.M., VALADARES FILHO, S.C., COELHO DA SILVA, J.F. et al. Consumo e digestibilidades aparentes totais e parciais de dietas contendo diferentes níveis de concentrado, em novilhos nelore. Revista Brasileira de Zootecnia, v.28, n.2, p.395-403, 1999.

LEÃO, M.I., COELHO DA SILVA, J.F. Técnicas de fistulação de abomaso em bezerros. In: CONGRESSO BRASILEIRO DE ZOOTECNIA, 1., REUNIÃO ANUAL DA SOCIEDADE BRASILEIRA DE ZOOTECNIA, 17., 1980, Fortaleza. Anais... Fortaleza: Sociedade Brasileira de Zootecnia, 1980. p.37.

MERTENS, D.R. Analysis of fiber in feeds and its use in feed evaluation and ration formulation. In: SIMPÓSIO INTERNACIONAL DE RUMINANTES, 1992, Lavras, MG. Anais...Lavras: Universidade Federal de Lavras, 1992.p.1-32.

NATIONAL RESEARCH COUNCIL - NRC. Nutrients requirements of beef cattle. 6.ed. Washington, D.C.: National Academy Press, 1984. 90p.

NATIONAL RESEARCH COUNCIL - NRC. Ruminant nitrogen usage. Washington, D.C.: National Academy Press, 1985. $138 \mathrm{p}$.

NATIONAL RESEARCH COUNCIL - NRC. Nutrients requirements of beef cattle. 7.ed. Washington, D.C.: National Academy Press, 1996. 244p.

OLSON, K.C.; COCHRAN, R.C.; JONES, T.J. et al. Effects of ruminal administration of supplemental degradable intake protein and starch on utilization of low-quality warm-season grass hay by beef steers. Journal of Animal Science, v.77, p.1016-1025, 1999.

POORE, M.H., MOORE, J.A., SWINGLE, R.S. Differential passage rates and digestion of neutral detergent fiber from grain and forages in 30,60 e 90\% concentrate diets fed to steers. Journal of Animal Science, v.68, p.2965-2973, 1990.

RABELLO, T.G. Grão de soja moído na alimentação dae vacas lactantes. Viçosa, MG: Universidade Federal de Viçosa, 1995. 114p. Dissertação (Mestrado em Zootecnia) Universidade Federal de Viçosa, 1995.

RUSSELL, J.B. Strategies that ruminal bacteria use to handle excess carbohydrate. Journal of Animal Science, v.76, p.1955-1963, 1998.

RUSSELL, J.B.; O'CONNOR, J.D.; FOX, D.G. et al. A net

R. Bras. Zootec., v.31, n.3, p.1543-1552, 2002 (suplemento) 
carbohydrate and protein system for evaluating cattle diets. 1. Rumen fermentation. Journal of Animal Science, v.70, n.11, p.3551-3561, 1992.

SILVA, D.J. Análise de alimentos (Métodos químicos e biológicos). Viçosa, MG: Universidade Federal de Viçosa. 1990. 165p.

SILVA, F.F. Desempenho, características de carcaça, composição corporal e exigências nutricionais (energia, proteína, aminoácidos e macrominerais) de novilhos Nelore, nas fases de recria e engorda, recebendo diferentes níveis de concentrado e proteína. Viçosa, MG: Universidade Federal de Viçosa, 2001. 211p. Tese (Doutorado em Zootecnia) - Universidade Federal de Viçosa, 2001.

SNIFFEN, C.J.; O'CONNOR, J.D.; Van SOEST, P.J. et al. A net carbohydrate and protein system for evaluating cattle diets. 2. Carbohydrate and protein availability. Journal of Animal Science, v.70, n.11, p.3562-3577, 1992.

TIBO, G.C.; VALADARES FILHO, S.C.; COELHO DA SILVA, J.F. et al. Níveis de concentrado em dietas de novilhos mestiços F1 Simental x Nelore. 1. Consumo e digestibilidades. Revista Brasileira de Zootecnia, v.29, n.3, p.910-920, 2000.

UNIVERSIDADE FEDERAL DE VIÇOSA - UFV. Central de Processamento de dados (UFV/CPD). Manual de utilização do Programa SAEG (Sistema para Análises Estatísticas e Genéticas). Viçosa, MG: Universidade Federal de Viçosa, 1997. 59p.
VALADARES FILHO, S.C. Digestão total e parcial da matéria seca e carboidratos em bovinos e bubalinos. Viçosa, MG: Universidade Federal de Viçosa, 1985. 147p. Tese (Doutorado em Zootecnia) - Universidade Federal de Viçosa, 1985.

VALADARES FILHO, S.C. Eficiência de síntese de proteína microbiana, degradação ruminal e digestibilidade intestinal da proteína bruta em bovinos. In: SIMPÓSIO INTERNACIONAL SOBRE EXIGÊNCIAS NUTRICIONAIS DE RUMINANTES, 1995, Viçosa, MG. Anais...Viçosa: Universidade Federal de Viçosa, 1995. p.355- 388.

VALADARES FILHO, S.C.; RODRIGUEZ, N.M.; INFANZÓN, R.R.V. et al. Digestão total e parcial de fenos de soja perene em ovinos. 1. Matéria seca e energia. Revista da Sociedade Brasileira de Zootecnia, v.16, n.2, p.131-139, 1987.

Recebido em: 10/08/01

Aceito em: 13/02/02 